\title{
Strategies of College English Assignment Designing from the Perspective of MI Theory*
}

\author{
Jinxiu Jing \\ School of Foreign Languages, Leshan Normal University, Leshan, China
}

\begin{abstract}
College English assignment should be oriented at consolidating and extending what students have learned in the class, realizing the role of promoting students' English learning and even their all-round development. And a comprehensive achievement could be better reached if college English teachers employ the Multiple-intelligences Theory in the process of designing assignment, catering to aptitude and individuality.
\end{abstract}

Index Terms-Multiple-intelligences Theory, college English, assignment

\section{Current Situation of College English Assignment}

Assignment, as an essential part of college English class, belongs to a system of English teaching. However, current researches show that assignments are always neglected because most of teachers find it tiring and time-consuming to check assignment, while they need the time to do research work and giving class. Or, even some of them just ask students to do some written tests without considering students' learning styles, thus neglecting the necessity of individual development. Tan (2009) holds that college students always spend much time on rote-learning, thus failing to utilize their potentials and cultivate abilities of thinking and working independently. Unscientific assignments will make students learn passively, and therefore, they could not accomplish the target of consolidating and extending what they have learned in class (Shi, 2008)

\section{FeAtures of College English Assignment}

English assignment is a kind of purposeful teaching activity that teachers prescribe students to finish, and it mainly has three features.

First, assignment is an approach to consolidate what students have learned in class. Teachers need to check how much students have acquired and their understanding in class. However, those aspects could not be finished just in class, and then teachers need to give students some additional after-class tasks as a complement to the English teaching. As well, teachers can adjust teaching accordingly and reflect their teaching. Besides, this is also a kind of bond between students and teachers as a way to ensure the successful English class interaction in class.

Second, assignment enables students to take up more challenges in terms of English learning, and absorb more extracurricular knowledge. The traditional English class hour is intense but short, so it is impossible to accomplish systematic learning just in class. Therefore, students need more tasks and guidance to explore English as well as their potentials, while teachers' guidance is unavoidable. Teachers could lead students to do some practice, helping them to review language points, so as to encourage students to be more responsible and active in English learning.

Third, assignment develops students' comprehensive ability. English class is to enhance students' development as a whole person and, at the same time, and stressing on language learning. Traditionally, English assignment in China is mainly about rote-memorizing, testing, translation, seldom focusing on what teachers can help students' personal future development. It goes without doubt teachers mean well to help students finish some practical exercise like translation, reading and mechanically to pass the exams such as CET4/6(College English Test Band 4/6), while this exam-oriented exercise alone could contribute to students sound development physically and physically.

From the current situation and typical features of English assignments in China, it is imperial for teachers to adopt new concept to design English assignment so as to promote college students' comprehensive development.

\section{THEORETICAL BASIS}

College English Curriculum Standards (2007) stipulates that the main target of college English teaching are cultivating students comprehensive ability of using English, especially listening and speaking, ensuring that they can communicate successfully in their future learning, work and daily life, strengthening the ability of automatic learning, improving their comprehensive literacy, better adjusting themselves to the development of our country and international communication. Seeing the above, it can be drawn that college English assignment is related to not only students' English learning, but also further development.

\footnotetext{
* This research is financed by the Research Projects of Leshan Normal University (No.S0948).
} 
Gardener (1999) holds that human beings would make greater contribution to society as long as we can make take advantage of all abilities. The Multiple Intelligences theory (MI theory) put forward by Gardner claims that each person possesses different combinations of ninth intelligences, namely, mathematical-logical intelligence, musical intelligence, verbal-linguistic intelligence, visual/spatial intelligence, bodily/kinesthetic intelligence, interpersonal intelligence and intrapersonal intelligence, naturalist intelligence and existential intelligence. The above nine intelligences are not forever fixed; instead, they can be developed and used to develop on a certain condition. Each individual has a different combination of intelligence, which explains that we deal with things in different ways.

In education, it advocates that teachers should address students' personal uniqueness and provide a wide range of intelligence-oriented activities and experiences to facilitate learning, which is consistent with the core idea of the College English Curriculum Standards, that is, English teaching is not only for knowledge, but for the all-round development and the individuality of every student as well. Gardner holds that it is impossible to find individuals having the same intelligence combination, while it is possible to finds people having highly developed intelligences and thus personalized learning styles. Teachers should admit and cater to intelligence disparity, offering education according to students' aptitude, respecting individuality, and offering students an environment that helps students display their highly-developed intelligence while improving weak intelligences. Since MI theory came into being since 20 more years ago, it has a great effect on education with the teaching practices in many countries and areas around the world.

\section{PRINCIPLES OF DESIGNING AssignMENTS}

\section{A. Principle of Individuality}

MI theory advocates that each individual has his/her unique combination of intelligence, which corresponds to the needs of young people on college campus. They care more about their individual development, hoping to display perfect images on different campus occasions, for they have begun to explore what they want to achieve in future. Therefore, when designing assignments, teachers need to bear in mind that everyone has nine intelligences, which call for improvement and that weak intelligence should be promoted to be strong intelligences, instead of being neglected For instance, after learning a topic about music, after-class activities for checking understanding could be carried out by asking students of verbal intelligence to write lyrics and essays, students of music intelligence to compose rhythms, students of bodily/kinesthetic intelligence to dance or students of visual/spatial intelligence to decorate the stage or draw their understanding with colors, etc. if students express their understanding of the topic in a personalized approach, they will feel that they are respected; in the meanwhile, teachers will be more adept in exploring interest-arousing assignment.

\section{B. Principle of Subject}

Since MI theory promotes an active perspective at students, namely, the real subjects of the class, and it claims that students are different in terms of intelligence combination, learning styles and learning strategies. As a result, teachers need to create different contexts for students to display themselves, making students the center of the class, respecting students' intelligence and thus putting forward their all-round development. It would be better if students actively develop intelligence-catering activities automatically, pouring new ideas and creations into the choices of assignments. Besides, after getting away from the intense learning in high school, college students have more free time at disposal. Therefore, students at this age are eager to improve and enhance their capacities as well as practical skills in dealing with social problems; meanwhile, they need some assistance from the people around to guide them and parents, peers and teacher are the suitable people. As a result, it is significant and beneficial to help students to experience the joy of creation and exploring ways for self-fulfillment.

\section{Principle of Enjoyment}

MI theory emphasizes individuality, so teachers should try to brainstorm more activities which arouse students' interest and enjoyment. Only when they convert the class of "teaching to books" into "teaching to aptitudes", students will be motivated to do the assignments. If teachers are able to offer activities attracting students' curiosity, students will keep an eye on the class (Harmer, 2000). For instance, after-class activities for Unit 7 "Food and Health' in Chuangxin College English (2) may be fulfilled in the following forms: basics about healthy food, debating/parallel writing, poster designing/drawing, songs and dances, etc. Students are free to choose 1-2 items, in this way, assignments can not only ensure students' enjoyment of exploring daily life, but also consolidate what they have learned in class. If teachers try to conduct the real MI-based assignment projects, they need to take students as unique individuals with their own intelligence combinations, and should try to design more interesting tasks fit for students' cognitive development so that they can easily experience the sense of involvement.

\section{Principle of Cooperation}

An individual could bring out a better performance as long as he/she succeeds in making use of most of their intelligences work together, and the same goes to English learning. Besides of the individual assignments which call for students to finish separately, so as to train their abilities of solving problems independently, there should be also activities which endow students chances to cooperate with each other, developing their skills of expressing themselves 
and understanding others. Only teachers encourage students to take part in group work, new ideas can come out in the process of communicating, and thus push forward their all-round development. Activities can range from visiting/ interviewing from projects, etc. Those activities can both accumulate their successful life experiences and cultivate their skills of cooperation and life-exploration.

\section{TYPES OF ASSIGNMENT}

Under the guidance of MI theory, teachers should try to ensure each student chances to display their strong intelligences and improve the weak intelligences. Therefore, teachers can document students' intelligence combinations, bearing in mind that each college student in a classroom are unique. MI theory provides us with a new perspective to view intelligence, and scientific evidence to come up with teaching activities that concentrate on individuality (Christison, 1999). In the meantime, teachers can also invite students to be involved in designing after-class activities, helping them to be the real subject of learning. To design assignments based on MI theory, there are always three goals to be addressed, namely, exploration (encourage students to take advantages of intelligences through joining in activities); talent development (provide students with ample chances for them to exercise of abilities); and using strengths (create more accentuating students' intellectual strengths in their curriculum, paying attention to individualized or personalized education). Here, the author will recommend some activities according to the features of each intelligence.

Verbal/Linguistic Intelligence allows individuals to communicate and make sense of the world through language. Teachers can design assignments through listening, debate, storytelling, individualized reading, intensive and extensive reading, writing, keeping a diary or journal, etc.

Logical/Mathematical Intelligence enables individuals to use and appreciate abstract relations and understand the underlying principles of some kind of causal system. Teachers can guide students to do T/F questions, riddles, rewriting stories, sequencing paragraphs, bringing out solutions, etc.

Visual-Spatial Intelligence instills people the capacity to think in three-dimensional ways. This intelligence involves sensitivity to color, line, shape, form, space, and the relationships that exist between among elements. Assignments could be carried out by asking students to drawing pictures to express their understanding of the text, designing posters, watching videos and making use of colors to highlight the key points.

Bodily/Kinesthetic Intelligence enables individuals to use one's body to express opinion and feeling as well as the facility to manipulate objects skillfully. Students could be encouraged to finish after-class tasks through role-playing, dancing to memorize vocabulary, "hands-on" activities, facial expressions, physical relaxation exercises, role playing/drama, learning a topic or idea with a physical gesture associated.

Musical Intelligence allows people to create, communicate, and understand meanings made out of sound. Students can be encouraged to express themselves through creating lyrics about the material being taught, singing, playing instrument, listening to music, rhythm, composing.

Interpersonal Intelligence enables people to perceive and make distinctions in the moods, intentions, motivations, and feelings of other people. Students could cooperate to finish assignments by doing group projects, drama/role playing, simulation, subject drills with partners, quizzing each other, discussion, interviewing.

Intrapersonal Intelligence helps individuals to distinguish among their own feelings, to build accurate mental models of themselves, and to draw on these models to make decisions about their lives. Assignments could be expressed in terms of journaling, meditation, self-assessment, goal-setting, thinking about what has been learned, emotional processing, and guided imagery.

Naturalist Intelligence allows people to use, classify, and distinguish among features of the environment. Teachers can foster this intelligence by using relationships among systems of species, classification, comparing sets of groups, working in nature, exploring living things, creating observation notebooks of plant.

Existential intelligence is about posing and pondering questions about life, death and ultimate realities, and people of this style enjoy thinking, and questioning, and are curios about life, death, and ultimate realities. And college students are capable of questioning about in term of English.

Through students finish assignment in different ways, one point is assured, that is, the combination of English learning with developing intelligence, individuality, and personal interest. No intelligence can exist alone, and therefore efficiency of learning can be greatly promoted only when intelligences are involved. Therefore, in the process of designing after-class activities, teachers had better encourage students to make use of their intelligences, trying various approaches to learn English, which promotes English learning and develops their week intelligence.

Most teachers would agree that allowing students to learn in a way in which they are most comfortable will increase students' self-confidence as well as the possibility for substantive learning. In MI concept, everyone is appreciated for his or her uniqueness, and various MI-based activities are implemented to help students approach learning with confidence and joy for effective learning. Therefore, this kind of assignment appears to be especially crucial for college students as they are still establishing self-image from the ones surrounding them. Bearing in mind MI theory, it is easier to design a variety of assignment activities that cater to different needs and provide ample opportunities for students in different situations so as to exercise their unique intelligences. 


\section{Steps of Designing English Assignment Activities Through Mi TheORY}

With the reference of Christison (1996), the author lists four steps to show how MI theory is applied to college English assignment designing.

(1). Setting Teaching Objective

For designing after-class activities, the most important objectives are still to help college students develop their own comprehension of the texts and enhance necessary language skills at the same time. Teachers should also try to use nine different ways to help students gain necessary learning skills, promoting balanced development of students multiple intelligences as well.

(2). Reviewing the List of MI-based Activities

It requires teachers to handle activities in a more agile and delicate way. Adult students will turn away once they find the activities dull. How can a teacher always keep the tasks attractive and interesting, and meanwhile conductive to the development of students' English learning and intelligences? As Gardner (1995) states, "The more ways you teach, the more people you reach". Teachers need to refer to various MI-based activities and keep searching for more new effective ones.

\section{(3). Choosing Appropriate Activities}

Not all students are exactly the same. Therefore, in designing activities for English assignments, teachers should take into the followings into consideration: students' needs analysis, strengths, learning levels, personal interest, etc. Armstrong (2000) in his article "Multiple Intelligences: Seven Ways to Curriculum" suggested that teachers use the following questions as a checklist when developing plans: How can I use spoken or written language (Linguistic)? How can I include numbers, computation, logic, classification, and critical thinking (Logical/mathematical)? How can I use videos, visualization, visual organizers, color, and art (Spatial)? How can I include musical sounds, environmental sounds, and rhythm (Musical)? How can I include movement, hands-on experience, and eye-hand coordination (Bodily/kinesthetic)? How can I involve students in cooperative groups, peer or cross-age tutoring, and large-group role-playing (Interpersonal)? How can I elicit memories, personal feelings, or present options (Intrapersonal)? How can I include classifying, observing, or environmental appreciation (Naturalist) (added by the author)? In choosing activities, teachers should avoid the dangers of just making students have fun in the process without get anything beneficial to their further study. Combining fun and English learning together is the key to a successful assignment.

(4). Reflection

At this stage, teachers need to track down what intelligence has been trained s by checking the MI weekly/monthly checklist, and later explore the other intelligence-related activities in the following class hours. Through this, teachers can reach the goal of catering to each intelligence in and out of the classroom, helping every student develop in an all-round way.

\section{ASSESSMENT UNDER THE GUIDANCE OF MI THEORY}

\section{A. A New Concept of Students and Teachers}

If teachers are trying to employ MI theory designing English assignment, they had better have a through look at the brand new role of students and teachers in the framework of MI theory. Gardner holds that each individual own nine intelligences, which are displayed in various form and in different combinations. Therefore, there must be disparity among the development of intelligences, and English learning, as a way to cultivate human culture and intelligence, should be adjusted to satisfy students intelligence development. When teachers admit intelligence diversity, it means that we should encourage individuality in our classrooms. If we can appreciate human beings' intelligence and learning capacity in a scientific and logical perspective, we will fully understand the uniqueness of each student because of their unique intelligence combinations and learning styles, so as to promote equality in classrooms (Huo, 2003).

On the basis of admitting intelligence equality and diversity, teachers need to realize that English learning and developing students' intelligences are of the same importance. English students should enjoy the same education and therefore, they will get a sound development in the long run to be a useful person in society. The traditional English class just judge students simply with the standards of language tests, neglecting most students' strong intelligence and thus their learning styles. Actually, English teaching should provide students a cultural environment which promotes each intelligence of students; and with the encouragement and guidance of teachers, everyone is made to be successful, instead of some special ones. At the same time, it is also necessary to encourage students to know their intelligence combination and cognitive style, cultivating their active involvement in language learning, planning and monitoring. Teachers need to care for each student and design assignment according to their multiple intelligences, trying to help students display strong intelligence and improve weak intelligence in the process of doing assignment. MI theory offers us a new perspective at students, assisting teachers in designing more assignments which focus on individual difference (Christison, 1999).

\section{B. Comprehensive Development of Intelligence}

Nine intelligences can stand separately while also work collaborately, but people need to solve problems with all of their involvement; nearly each person, whatever his/her social background is, needs combining several intelligences to 
work out problems (Gardner, 1983). The related neurological system will not function properly or even disappear gradually, if there is no suitable condition and training fit for intelligences. Education plays a great role in digging out a person's potential. Once a person is provided with a chance to make use of his/her potential and learn, they will definitely show a positive change in their cognition, mood, and even physical functions. MI theory advocates that people are born with intelligences, which can be promoted to a higher level with proper practice and guidance. The intelligences are interrelated and improved mutually; even sub-intelligences of each intelligence are in the above connections. In English leaning the subsystems of lingual intelligence, namely, listening/reading/ speaking/writing intelligences are related mutually, so it is scientific to promote the whole development of lingual intelligence by using the connections of these sub-skills. Therefore, in the assessment process, teachers need to combine the inner connections of intelligences and its subsystems. Learners of intelligence could take advantage of their verbal/linguistic intelligence to help the further development of other intelligences.

\section{Multiple Forms of Assignment}

English teaching is students-centered from the perspective of MI theory, advocating task-based teaching. Teachers help students' explore and employ their own strong intelligences, or combinations of intelligence to learn English, and help their comprehensive development of four language skills. Also, teaching should not just be limited to class hour, but also extend to students' out-class learning and daily life. English assignment is an approach to help the extending process, an improvement way to help students' extracurricular courses. Here are features of assignment under MI guidance. a. teachers need to assign individualized tasks according to students' multiple intelligence; b. intelligence development should be embodied in tasks, which vary in amounts and degree of difficulty; c. answers and forms of assessment are open, for students are allowed to choose different tasks, forms, and content; $\mathrm{d}$, the objectives are related to students daily life, helping students experience success and self-realization.

\section{Multiple Forms of Evaluation}

Assessment needs to be realized in different approaches from the perspective of MI theory. Teachers should develop more formative assessment, including self-assessment, peer assessment, teacher assessment, etc., and teachers need to advocate the use of portfolios. First, teachers can encourage students to be involved in the project of self-assessment. This calls for cooperation of both teachers and students in planning and making assessment criteria. When students are involved in assessment of themselves, their friends, their intelligences of intrapersonal, interpersonal, naturalist intelligence are all practiced. In a word, teachers' assessments are just one small part, with respect to students' self-assessment. Intelligences should be the real performance of individuals in a learning environment; therefore, it can only be evaluated in a certain cultural background, instead of single tests (Armstrong, 1994) .This explain why assessment in MI theory are implemented in various forms and standards, because the real purpose of assessment is to help students' intelligence development.

\section{CONCLUSION}

In order to promote efficiency of English assignments while allowing students space to display their specialties, developing weak intelligences, it is advocated that, in and out of class, English teachers should take students' intelligence development into consideration, coming up with diverse activities. The concept of exploring more significant after-class activities under the guidance of MI theory enables students be to more confident and active in displaying themselves, developing students' cooperation and training their strong will. It is beneficial for them to explore English learning and personal future development through various forms of activities, fertile imagination, flexible assessment and autonomy to be involved in assignment designing. Currently, education in China is in an era of reform and creation, especially, the transformation of examination-oriented education to education for all-round development, so college English assignment will also definitely embrace its evolvement with the implementation of College English Curriculum Standards. Teachers should reconfigure the traditional assignment design, and Gardner's MI theory can provide profound implications for this reconfiguration.

\section{REFERENCES}

[1] Armstrong, T. (1994). "Multiple intelligences: Seven ways to approach curriculum.” Educational Leadership, 52:26-28.

[2] Armstrong, T. (2000). Multiple intelligences in the classroom. Alexandria: Virginia: Association for Supervision and Curriculum Development.

[3] Chinese Ministry of Education. (2007). College English curriculum standards. Beijing: Tsinghua University Press.

[4] Christison, M.A. (1996). Teaching and learning language through multiple intelligences. TESOL Journal, 6(1): 10-14.

[5] Christison, M.A. (1999). A guidebook for applying multiple intelligences theory in the ESL/EFL classroom. Burlingame, CA: Alta Book Center.

[6] Gardner, H. (1983).Frames of mind: The theory of multiple intelligences. New York: Basic Books

[7] Gardner, H. (1995). Reflection on multiple intelligences: Myths and messages. Bhi Delta Kappan.

[8] Gardner, H. (1999a). Intelligence reframed: Multiple intelligences for the 21st century. New York: Basic Books.

[9] Harmer, J. (2000). How to teach English. Beijing: Foreign Language Teaching and Research Press.

[10] Huo, Liyan,.(2003). MI theory and the Art of Education. Comparative Education Review. Vol. 3, 63-65 
[11] Shi, Qinlin. (2008).On college English assignment designing based on MI Theory. Journal of Huzhou Normal University. Vol.3, $125-127$

[12] Tan, Yufei. (2009).On university teaching style in America. Research of Heilongjiang University Education. Vol.7, :49-51

Jinxiu Jing was born in Shehong, China in 1983. She received her master degree in linguistics from Southwest University, China in 2008 .

She is currently a lecturer in the School of Foreign Languages, Leshan Normal University, Sichuan, China. Her research interests include English teaching research. 